\title{
Structural Connections for Small-Diameter Poles
}

\author{
Telmo F. M. Morgado'; Alfredo M. P. G. Dias²; José S. Machado ${ }^{3}$; and João H. Negrão ${ }^{4}$
}

\begin{abstract}
In Portugal, given the large proportions of natural regeneration pine stands, a large amount of young trees must be removed from the forest, to assure the quality of mature trees and to decrease the risk of fire. With this problem in mind, a national study was launched to investigate the use of maritime pine small-diameter poles in structural applications. The study had two different tasks. The first task comprised the determination of mechanical properties and the establishment of visual and mechanical strength grading procedures and is already completed. The second task concerns the development of connections. This paper presents results within the second task. Three types of connections, regarding failure load and stiffness, were studied: connections using central plates; glued-in rods; and dowel nuts. The glued-in rods showed the highest mean failure load and, especially, stiffness. Indeed, the glued-in rods showed a mean stiffness around six times higher than the one obtained for the other studied connections. Additionally, the applicability of European Yield Model to estimate the failure load of these connections is also discussed. DOI: 10.1061/(ASCE)ST.1943-541X.0000752. () 2013 American Society of Civil Engineers.
\end{abstract}

CE Database subject headings: Connections; Rods; Load factors; Stiffness; Dowels; Portugal.

Author keywords: Roundwood; Connections; Glued-in rod; Dowel nut; Central plate; Failure load; Stiffness.

\section{Introduction}

Usually, stands of Portuguese forest maritime pine (Pinus Pinaster Ait.) are the result of natural regeneration. Therefore, pine stands generally present a narrow spacing showing a large number of young trees per hectare that, if removed in due time, could increase the quality of mature trees and decrease the risk of fire. With this problem in mind, a study was launched to investigate the use of maritime pine smalldiameter poles for structural applications. The study had two different tasks. The first task comprised the determination of the mechanical properties, the establishment of a Portuguese visual strength grading standard, and a proposal for a certification scheme to support the grading process. The results of the first task, which can be found in Morgado et al. (2009), showed the excellent mechanical properties of small-diameter roundwood timber for structural application. The second task concerns the development of connections to allow the roundwood structural application. This paper presents the results obtained within this second task.

Roundwood is a suitable material for trussed systems of, mainly, roofs and bridges. In these structural applications the small sections,

${ }^{1}$ Ph.D. Candidate, Dept. de Engenharia Civil, Faculdade de Ciências e Tecnologia, Universidade de Coimbra, Rua Luís Reis Santos, Pólo II da Universidade, 3030-788 Coimbra, Portugal (corresponding author). E-mail: telmo.morgado@gmail.com

${ }^{2}$ Assistant Professor, Dept. de Engenharia Civil, Faculdade de Ciências e Tecnologia, Universidade de Coimbra, Rua Luís Reis Santos, Pólo II da Universidade, 3030-788 Coimbra, Portugal. E-mail: alfgdias@dec.uc.pt

${ }^{3}$ Officer Researcher, Laboratório Nacional de Engenharia Civil (LNEC), Núcleo de Estruturas de Madeira, Av. do Brasil, 101, 1700, 066 Lisboa, Portugal. E-mail: saporiti@lnec.pt

${ }^{4}$ Aggregate Professor, Dept. de Engenharia Civil, Faculdade de Ciências e Tecnologia, Universidade de Coimbra, Rua Luís Reis Santos, Pólo II da Universidade, 3030-788 Coimbra, Portugal. E-mail: jhnegrao@ dec.uc.pt

Note. This manuscript was submitted on May 16, 2012; approved on September 27, 2012; published online on September 29, 2012. Discussion period open until April 1, 2014; separate discussions must be submitted for individual papers. This paper is part of the Journal of Structural Engineering, Vol. 139, No. 11, November 1, 2013. @ASCE, ISSN 0733-9445/ 2013/11-2003-2009/\$25.00. length and weight, when compared with steel, can be an advantage. Moreover, having in mind the current issue of sustainability, roundwood is a renewable and environmentally friendly material. Nevertheless, before the roundwood can be used to its full potential in structural applications, suitable solutions for connections must be found (Stern 2001).

The issue of developing efficient connectors for roundwood elements has been the target of several studies. However, available connections for roundwood are expensive, hard to implement, have esthetic problems, and must be designed for each particular case, not allowing mass production of connections (Yeates 1999; Wolfe 2000).

In this study the main intended applications for the smalldiameter roundwood, as stated previously, will be in trussed systems. For this reason, connections that are suitable for this kind of application will be the focus of the analysis. An extensive review of roundwood connections is presented by Lukindo et al. (1997). From that review, the connections that presented more potential for this specific application were the dowel nut and the central plate, because they are suitable to transfer compression and tension stresses and are also easily connected to nodes. In this study a third possibility was considered on the basis of use of glued-in rods. This type of connection has been tried in other applications and it fulfills the requirements of the roundwood connections for this study. For these reasons, configurations using glued-in rods were developed and tested in this work. These three types of selected connections are further detailed.

The connections with central plates require a slot across the pole's diameter to allow the insertion of the plate. The plate is then connected to the pole through dowels or bolts. Bands or wires can be placed around the connectors and the plate could be ridged to improve the failure load (Lukindo et al. 1998; Lukindo et al. 1997; Houtman et al. 1998). These connections have esthetic problems; nevertheless, they have a good potential in terms of failure load, as it can be easily improved with a higher number of fasteners or fasteners with larger diameter.

The dowel nut connections are made with a through bolt, placed in a longitudinal hole through the pole center, and a dowel nut, placed transversely in the section, such as in the studies of Eckelman 
and Senft (1995) and Wolfe et al. (2000). Instead of a dowel nut a metallic block can be used, as presented by Sluis et al. (1998). These connections require a high level of precision to assure the correct position of the longitudinal hole and the transversal hole. The high level of craftsmanship involved in the manufacture of this type of connection could be a disadvantage. On the other hand, this type of connection has less visual impact than the central plate connections.

The glued-in rods connections were studied mainly with glulam (Chans et al. 2009). Only a few studies with roundwood elements, using only one rod, can be found (Huybers 1996; Burton et al. 1998; Vale et al. 2011). This type of connection requires a hole in the end of the pole, where a steel rod is embedded, usually using an epoxy resin as the bonding media. This adhesive is a good solution because of its gap-filling properties. This connection has a superior esthetic when compared with that of the previous connections, because the visible metallic parts are much smaller. However, the failure of the connection might be brittle if governed by the glue. Moreover, deep holes require additional caution to assure that the air is not retained within the hole.

On the basis of that previously stated, the three types of connections were studied, using Portuguese maritime pine small-diameter roundwood. The configurations of the selected connections were optimized for this application and are different from the ones presented in other studies. Furthermore, the application of the European Yield Model and other formulations indicated in Eurocode 5 [European Committee for Standardization (CEN) 2002] to these connections are also discussed, to evaluate if they could be used to estimate their failure load and stiffness.

\section{Materials and Connection Description}

The poles for the connections were placed in a climatic chamber and were exposed to a relative humidity of $65 \%$ and $20^{\circ} \mathrm{C}$ of temperature, until the equilibrium moisture content was achieved. After that, poles were randomly selected and 50 elements with a length of $600 \mathrm{~mm}$ and a diameter between 95 and $140 \mathrm{~mm}$ were obtained for the central plate connections. Another 58 elements with a length of $600 \mathrm{~mm}$ and a diameter between 91 and $140 \mathrm{~mm}$ were obtained for the dowel nut connections. Finally, 85 elements with a length of $400 \mathrm{~mm}$ and a diameter varying between 96 and $174 \mathrm{~mm}$ were obtained for the glued-in rod connections. The segments were randomly selected on the basis of their straightness and absence of deep fissures or biological degradation.

A scheme of the central plate connections is presented in Fig. 1. The configuration was defined to maximize the failure load of the connections, but with a maximum length of $260 \mathrm{~mm}$. To assemble the connection, a slot with a length of $260 \mathrm{~mm}$ and a thickness of $10 \mathrm{~mm}$ across the element's diameter was opened. This was performed in both ends of the timber elements, assuring that the plates in each end are aligned. After that, two transversal holes with a diameter of $18 \mathrm{~mm}$ were made to place $18-\mathrm{mm}$ bolts. The spacing of

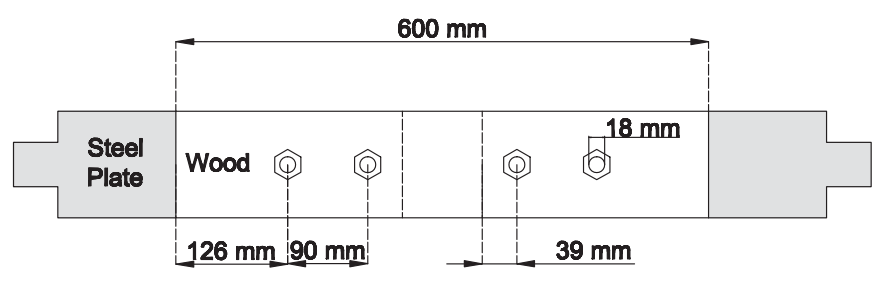

Fig. 1. Central plate connection schematics the fasteners followed the requirements of Eurocode 5 (CEN 2002), namely end distance of seven times the fastener diameter and an inner spacing of five times the fastener diameter. The bolts had a nominal strength of $800 \mathrm{MPa}$ and were $200 \mathrm{~mm}$ in length, and the plate had a section of $8 \times 120 \mathrm{~mm}$ and a nominal strength of $235 \mathrm{MPa}$.

The configuration of the studied dowel nut connection is presented in Fig. 2. This configuration, like in the previous typology, is the one with maximum failure load that could be tested, assuring the stated connection's length. To assemble these connections, a transversal hole of $30 \mathrm{~mm}$ diameter was made to place the $30-\mathrm{mm}$ diameter dowel. The placement of the dowel followed the requirements of Eurocode 5 (CEN 2002). So, an end distance of seven times the dowel diameter was followed. Another longitudinally centered hole of $18 \mathrm{~mm}$ diameter, meeting the transversal one, was made for the 16-mm rod. This was performed in each end of the timber elements, assuring that the dowels were aligned. The rod and the dowel had a nominal tensile strength of $800 \mathrm{MPa}$ and the length of the rod was $330 \mathrm{~mm}$, whereas the dowel had a length of $150 \mathrm{~mm}$. At the middle of the dowel's length a threaded hole was opened to fix the rod.

For the glued-in rod connections, because the diameter of the timber elements has direct influence in the number of rods and its diameter, it was decided to maximize the failure load of the connections. To this end a base configuration and two additional configurations were tested. A scheme of the configurations is presented in Fig. 3. This configuration consisted of four glued-in rods, with metric thread, placed in timber elements whose diameter varied between 120 and $140 \mathrm{~mm}$. The rods had a nominal tensile strength of $400 \mathrm{MPa}$ and a failure load around $32 \mathrm{kN}$. The hole had a depth of $100 \mathrm{~mm}$ and a diameter of $12 \mathrm{~mm}$, to assure a glue thickness around the rod of $1 \mathrm{~mm}$. This glue thickness was chosen to avoid excessive deformation due to the glue. The epoxy glue Icosit K101 TW was chosen because of its low viscosity. A minimum spacing of 2.5 times the rod diameter between the rod and the outer circumference of the timber section was used. Additionally, a spacing of five times the rod diameter between rods, in a square configuration, was also assured. These distances were based on those presented in a draft version of

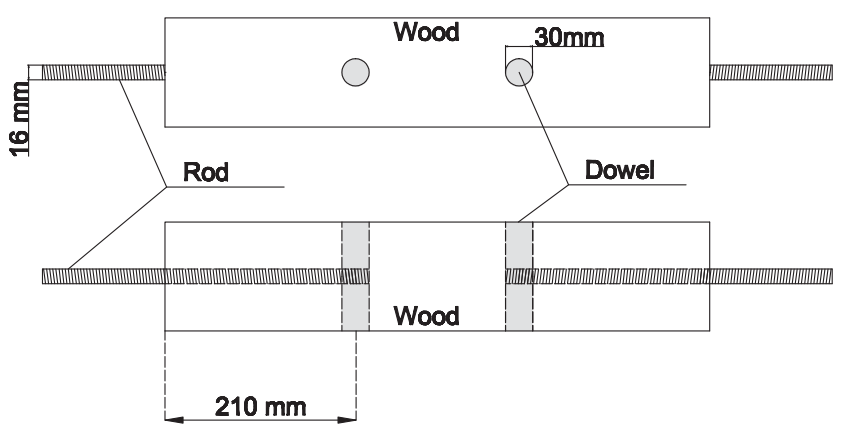

Fig. 2. Dowel nut connection schematics

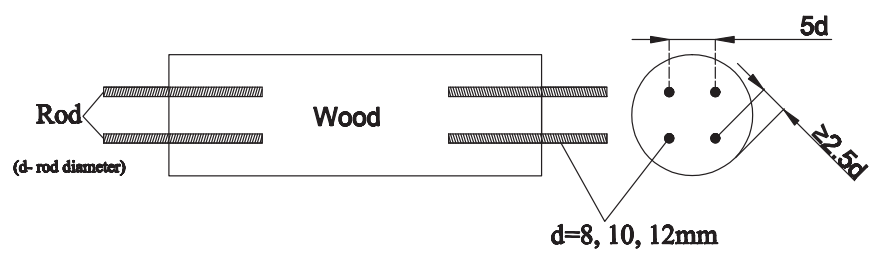

Fig. 3. Glued-in rod connection schematics 
part 2 of Eurocode 5 (CEN 2003). The definition of the bonding lengths were based on pullout tests that are presented in the next section.

The two additional configurations were performed with rods of 8 and $12 \mathrm{~mm}$ diameter. These rods had a nominal tensile strength of $400 \mathrm{MPa}$ and tension tests resulted in a failure load around 18.5 and $38.5 \mathrm{kN}$ for the $8-\mathrm{mm}$ rods and $12-\mathrm{mm}$ rods, respectively. The configuration of the rods was similar to the one presented before, being the depth of the holes again 10 times the rod diameter and the hole diameter $2 \mathrm{~mm}$ larger than it. The previously mentioned spacings were also assured. For the connections with 8-mm rods, timber elements with a diameter between 100 and $120 \mathrm{~mm}$ were

Table 1. Results of Pullout Tests

\begin{tabular}{lllllc}
\hline & \multicolumn{4}{c}{ Failure load (kN) } & \\
\cline { 2 - 5 } Depth $(\mathrm{mm})$ & Mean & Max & Min & Std & Number of Tests \\
\hline 50 & 23.82 & 30.65 & 19.21 & 3.33 & 22 \\
75 & 30.54 & 32.50 & 26.55 & 1.31 & 38 \\
100 & 31.37 & 33.85 & 28.63 & 1.16 & 36 \\
125 & 31.67 & 32.85 & 30.59 & 0.67 & 20 \\
\hline
\end{tabular}



(a)

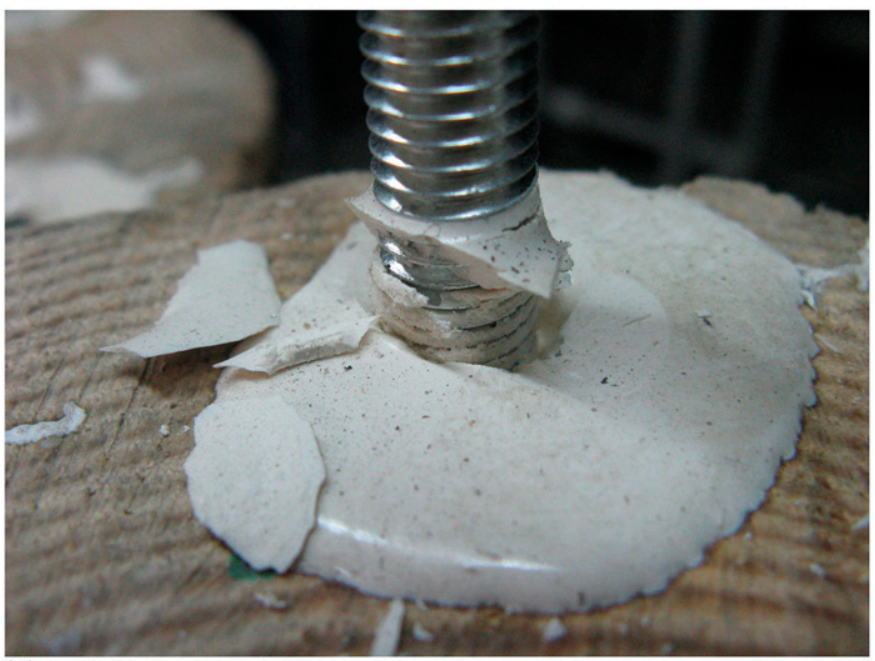

(b) used, whereas the 12-mm rods timber elements had a minimum diameter of $140 \mathrm{~mm}$.

\section{Experimental Procedure and Results}

The study to investigate the bonding length of the glued-in rods was done in 17 round timber elements with diameters between 186 and $241 \mathrm{~mm}$, allowing that various pullout tests were performed in each one. The timber density varied between 496 and $697 \mathrm{~kg} / \mathrm{m}^{3}$. In all tests $10-\mathrm{mm}$ rods with a nominal tensile strength of $400 \mathrm{MPa}$ were used.

Holes of $12 \mathrm{~mm}$ diameter and 50, 75, 100, and 125-mm depth were drilled in the timber elements, assuring a glue thickness of $1 \mathrm{~mm}$ around the rod. The holes were cleaned with air and the rods were cleaned with acetone to prevent bonding problems. After that, glue was inserted in the holes and then the rod, with a slow twist movement to avoid air into the glue. The results of the tests, $72 \mathrm{~h}$ later, are presented in Table 1.

The pullout tests with a depth of $50 \mathrm{~mm}$ presented mainly failures in the wood [Fig. 4(a)]. Nevertheless, in five tests the failure was in the adhesive [Fig. 4(b)]. The tests with a depth of $75 \mathrm{~mm}$ presented failures mainly by the rod (58\%), the remaining failures being in the wood (26\%) and the adhesive (16\%). In the tests with the depth of 100 and $125 \mathrm{~mm}$ the failures were in only the steel rods. On the basis of these results, it can be concluded that a bonding length of 10 times the rod diameter assures a failure in the steel rod, which is a preferable failure mode because of its ductile characteristics and low variation in terms of failure load.

Prior to the test of the connections a hinge was placed in the plate where the rods are threaded, to assure an equal force distribution in the four rods (Fig. 5). After that, the connections were placed in a testing machine to which the connections were attached and subjected to tension. It is important to state that this test arrangement allows the determination of the stiffness of two connections, but only the failure load of one. The test procedure followed the indications from the standard EN-26891 (CEN 1991). During the tests the load and displacement of each connection were continuously recorded. After the test, a full disk was cut from the middle of the timber element of the connection to assess the density and moisture content at the time of testing.

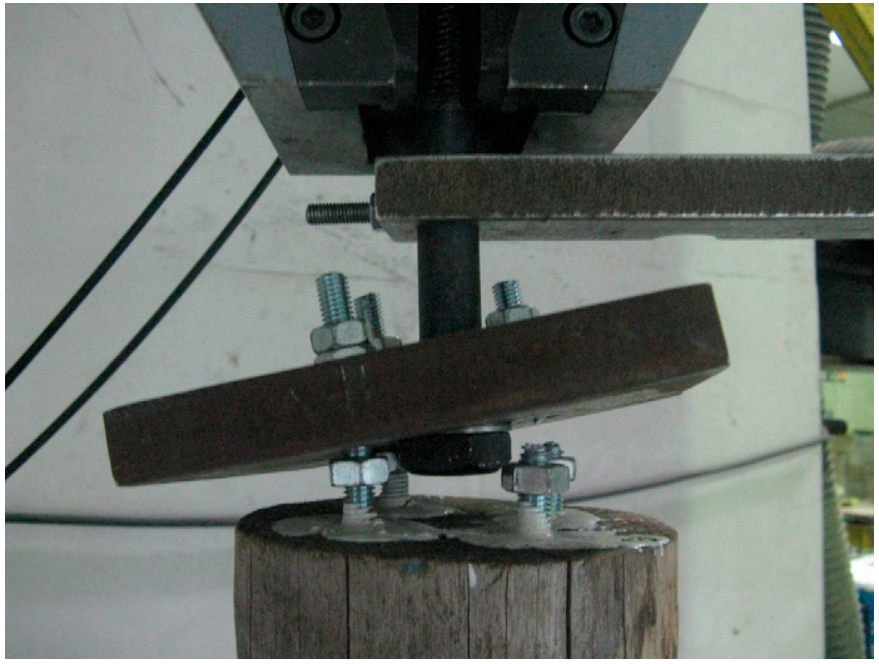

Fig. 5. Failure of a glued-in rod connection 
The failure of the glued-in rod connections, as expected, occurred in the steel rod (Fig. 5), with the exception of one connection on which there was a fissure next to a rod, which resulted in a failure in the wood. The results of failure load $(F)$ and stiffness $\left(K_{s}\right)$, determined according to EN-26891 (CEN 1991), together with density $\left(\rho_{12}\right)$ and moisture content $(w)$, are presented in Tables 2 and 3.

The failure of central plate connections occurred in the timber element because of fissures next to the fasteners [Fig. 6(a)]. Despite that, in connections on which the timber element had either a higher density or a higher diameter, the yielding of the bolts was clear [Fig. 6(b)]. Regarding the dowel nut connections, the failure was due to tension stresses perpendicular do the grain direction, which caused severe splitting (Fig. 7). No plastic deformations could be observed in the fasteners, either the dowel or the rod.

The results obtained for the central plate and dowel nut connections are presented in Tables 4 and 5, respectively. Likewise in

Table 2. Density and Moisture Content of Timber Elements of the GluedIn Rod Connections

\begin{tabular}{lccccccc}
\hline & \multicolumn{3}{c}{$\rho_{12}\left(\mathrm{~kg} / \mathrm{m}^{3}\right)$} & & \multicolumn{3}{c}{$w(\%)$} \\
\cline { 2 - 4 } \cline { 7 - 8 }$\phi$ rod $(\mathrm{mm})$ & 8 & 10 & 12 & & 8 & 10 & 12 \\
\hline Mean & 554.6 & 573.0 & 571.5 & & 13.2 & 13.3 & 13.2 \\
Max & 674.6 & 682.8 & 677.2 & & 14.1 & 14.0 & 13.9 \\
Min & 465.1 & 417.0 & 506.0 & & 12.1 & 12.0 & 12.2 \\
Std & 66.3 & 60.1 & 52.6 & & 0.6 & 0.6 & 0.6 \\
Number of tests & 19 & 50 & 15 & & 19 & 50 & 15 \\
\hline
\end{tabular}

Table 3. Failure Load and Stiffness of the Glued-In Rod Connections

\begin{tabular}{lccccccc}
\hline & \multicolumn{3}{c}{$F(\mathrm{kN})$} & & \multicolumn{3}{c}{$K_{s}(\mathrm{kN} / \mathrm{mm})$} \\
\cline { 2 - 4 } \cline { 7 - 9 }$\phi$ rod $(\mathrm{mm})$ & 8 & 10 & 12 & & 8 & \multicolumn{1}{c}{10} & 12 \\
\hline Mean & 74.1 & 126.5 & 155.3 & & 109.2 & 128.2 & 171.6 \\
Max & 75.6 & 133.3 & 158.9 & & 217.3 & 277.3 & 301.9 \\
Min & 71.5 & 111.9 & 151.0 & & 48.7 & 55.6 & 103.2 \\
$P_{0,05}$ & 71.8 & 119.2 & 151.6 & & 71.8 & 80.5 & 103.9 \\
Std & 1.1 & 4.0 & 2.2 & & 46.9 & 47.1 & 54.7 \\
COV (percentage) & 1.5 & 3.2 & 1.4 & & 42.7 & 36.7 & 31.9 \\
Number of tests & 19 & 50 & 15 & & 28 & 84 & 24 \\
\hline
\end{tabular}

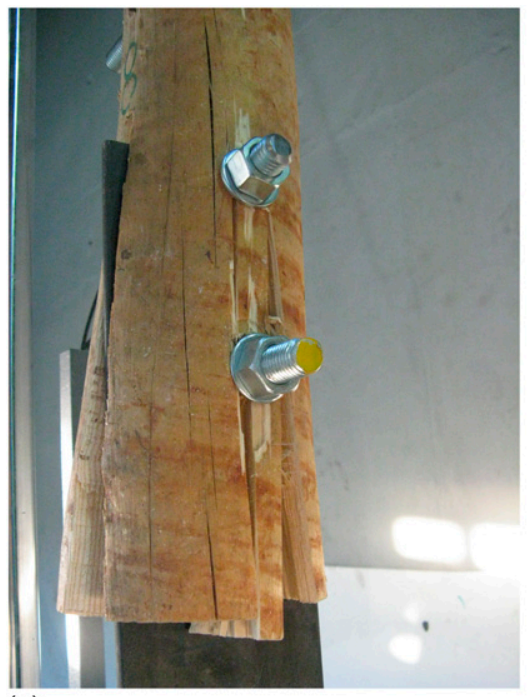

(a) the glued-in rod connections, some values of stiffness are not presented because they could not be measured.

\section{Discussion of Results}

Comparing the failure load of the studied connections, presented in Tables 3-5, it can be seen that the maximum failure load was obtained for the glued-in rod connections with 12-mm rods. Moreover, the ultimate load of glued-in rods had a coefficient of variation (COV) much lower, between 1.5 and $3.2 \%$, than that of the remaining connections. This yields in a fifth percentile very close to the mean ultimate load, for the glued-in rod connections, whereas for the remaining connections the fifth percentile of the ultimate load is much lower than its mean value. Indeed, although the mean and maximum failure load of the dowel nut and central plate connections were higher than the ones obtained for the 8-mm glued-in rods, the fifth percentiles of the failure load are similar.

The failure load of the central plate and dowel nut connections had a COV of 16.3 and $21.9 \%$, respectively. These results are higher than those (4-11\%) obtained for other types of timber connections made with dowel-type fasteners (Kuilen 1999; Dias et al. 2007), but close to $18 \%$, which is the reference COV for the compression strength of clear wood (USDA 2010). This is due to the fact that the failure load of these connections was governed mainly by the wood behavior.

To know which connection takes better advantage of the timber elements, because the poles presented a large range of diameters, the failure load expressed in terms of tension stress applied in the pole is presented in Table 6. It can be seen that no significant difference exists in the mean tension stress failure of the three types of connections studied.

The fifth percentile of the failure tension stress obtained for these connections is about $60-70 \%$ of the characteristic tension strength of the lower grade of Portuguese maritime pine sawn timber [Instituto Português da Qualidade (IPQ) 1995]. Based on this, it is expected that the connections should not limit significantly the design of a structure.

Comparing the values of stiffness $\left(K_{s}\right)$, presented in Tables 3-5, it is clear that the glued-in rods had much higher stiffness than the other connections. The stiffness also increases with the increase of the rod

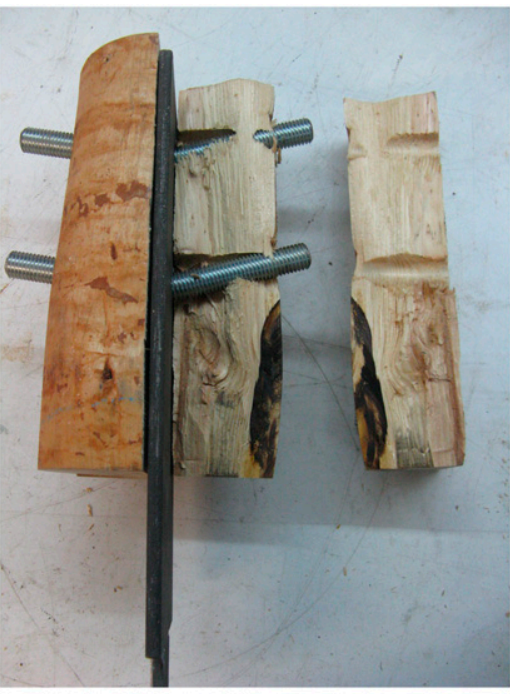

(b)

Fig. 6. Failure of central plate connections 


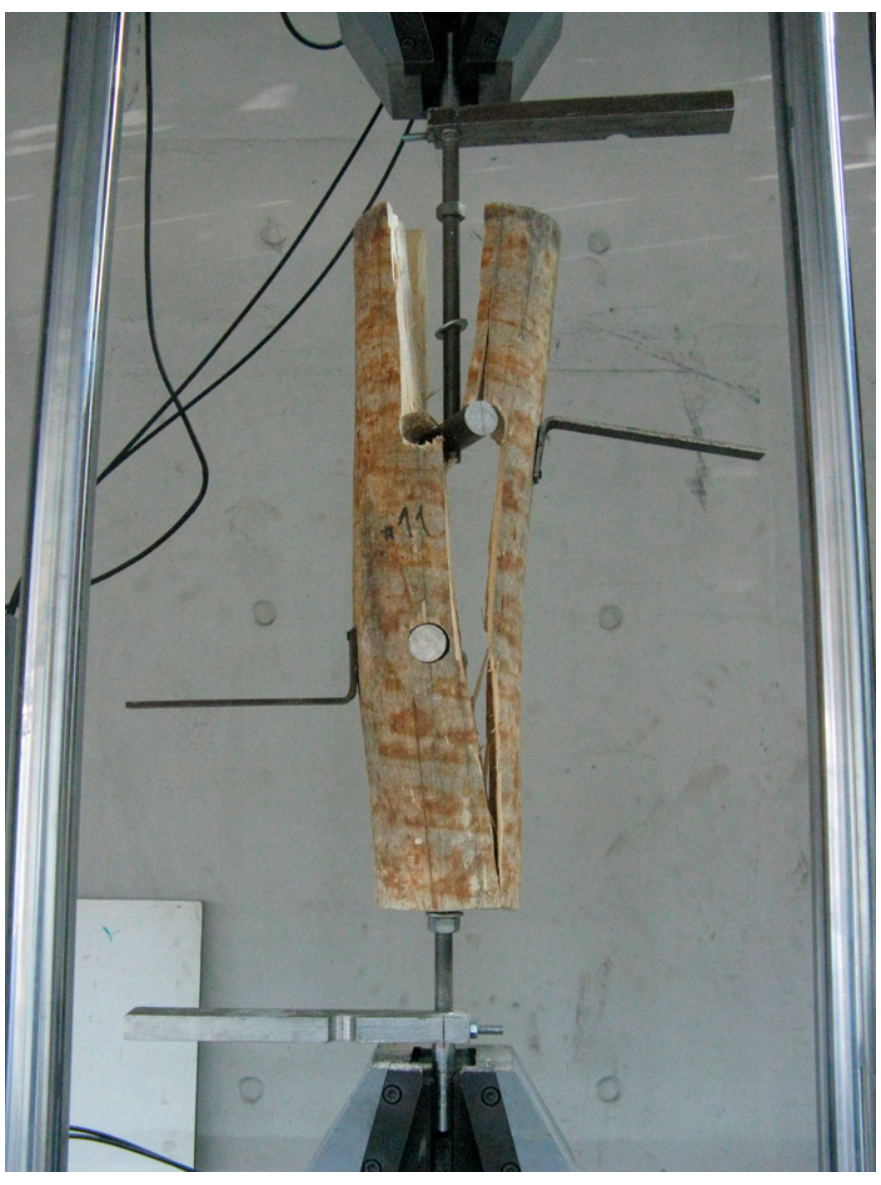

Fig. 7. Failure of a dowel nut connection

Table 4. Failure Load and Stiffness for the Central Plate Connections

\begin{tabular}{lcccc}
\hline & $F(\mathrm{kN})$ & $K_{s}(\mathrm{kN} / \mathrm{mm})$ & $\rho_{12}\left(\mathrm{~kg} / \mathrm{m}^{3}\right)$ & $w(\%)$ \\
\hline Mean & 112.0 & 31.6 & 552.0 & 13.6 \\
Max & 154.6 & 69.1 & 677.4 & 14.4 \\
Min & 70.8 & 15.6 & 430.3 & 12.3 \\
$P_{0,05}$ & 78.5 & 20.1 & 461.5 & 12.7 \\
Std & 18.3 & 10.0 & 54.8 & 0.5 \\
COV (percentage) & 16.3 & 31.6 & 9.9 & 3.7 \\
Number of tests & 47 & 94 & 53 & 47 \\
\hline
\end{tabular}

Table 5. Failure Load and Stiffness for the Dowel Nut Connections

\begin{tabular}{lcccc}
\hline & $F(\mathrm{kN})$ & $K_{s}(\mathrm{kN} / \mathrm{mm})$ & $\rho_{12}\left(\mathrm{~kg} / \mathrm{m}^{3}\right)$ & $w(\%)$ \\
\hline Mean & 94.9 & 29.3 & 558.4 & 13.7 \\
Max & 147.4 & 70.5 & 709.3 & 14.4 \\
Min & 52.2 & 15.1 & 445.6 & 12.8 \\
$P_{0,05}$ & 67.9 & 16.6 & 453.8 & 13.0 \\
Std & 20.8 & 11.9 & 63.4 & 0.4 \\
COV (percentage) & 21.9 & 40.6 & 11.4 & 2.9 \\
Number of tests & 58 & 113 & 58 & 58 \\
\hline
\end{tabular}

diameter, as it should be expected. The central plate and dowel nut connections showed similar stiffness values. The variability of the values was high in all connections, the COV being between 31.6 and $42.9 \%$. This result is higher than that $(28 \%)$ obtained experimentally for other types of timber connections made with dowel type fasteners (Dias et al. 2010). This high variability could be justified by the
Table 6. Failure Tension Stresses in the Studied Connections (MPa)

\begin{tabular}{|c|c|c|c|c|c|}
\hline & \multirow[b]{2}{*}{ Central plate } & \multirow[b]{2}{*}{ Dowel nut } & \multicolumn{3}{|c|}{ Glued-in rods (mm) } \\
\hline & & & 8 & 10 & 12 \\
\hline Mean & 10.9 & 9.8 & 8.0 & 10.1 & 8.7 \\
\hline Max & 16.3 & 13.6 & 10.1 & 12.5 & 10.1 \\
\hline Min & 5.6 & 6.1 & 6.5 & 7.5 & 6.4 \\
\hline$P_{0,05}$ & 6.6 & 7.2 & 6.9 & 7.7 & 7.2 \\
\hline Std & 2.4 & 1.7 & 1.0 & 1.3 & 1.1 \\
\hline COV (percentage) & 22.0 & 17.3 & 12.2 & 12.2 & 12.2 \\
\hline Number of tests & 47 & 58 & 19 & 50 & 15 \\
\hline
\end{tabular}



(a)

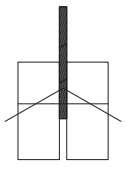

(b)

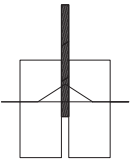

(c)
Fig. 8. Failure modes

variability of the wood and the increased error that is obtained when measuring such small displacements in real scale tests.

Regarding the load-deformation behavior, the central plate connections were the ones with higher deformation for the maximum load, presenting a mean value of $6 \mathrm{~mm}$, followed by the dowel nut connections with a mean ultimate load deformation of $4.4 \mathrm{~mm}$. The glued-in rods presented a much lower ultimate load deformation, with a mean value of $1.4,1.8$, and $2.0 \mathrm{~mm}$ for the $8-, 10-$, and $12-\mathrm{mm}$ rods, respectively. Moreover, the central plate connections were also the ones with higher plastic deformation, whereas the dowel nut connections presented almost no plastic deformations. This was expected, because the failure was caused by splitting of the timber with no yielding in the fasteners of the dowel nut connection.

The possibility of estimating the mechanical properties of the connections using correlations with the timber density was studied. Hence, for the central plate connections, a coefficient of correlation of 0.73 was obtained between the failure load and the density of timber. Between density and stiffness (mean value of the two connections per timber element) a coefficient of correlation of $r=0.46$ was obtained. For the dowel nut connections, density showed a correlation $r=0.56$ with failure load and a correlation of $r=0.51$ with stiffness. Regarding glued-in rods, no correlation between stiffness and density and between the density and the failure load was found.

Generally, density had a reasonable correlation with the mechanical properties of the connections, with exception of glued-in rods. This can be justified by the fact that the strength and stiffness of the glued-in rods connections are conditioned mainly by the steel. Then, the timber properties had less influence in the connections mechanical properties than in the other connections.

The European Yield Model formulations were also applied to the central plate and dowel nut connections to estimate their failure load. The model used was the double shear with a central plate. Three failure modes, which are presented in Fig. 8, were considered: Fig. 8(a) embedding in the timber; Fig. 8(b) embedding in the timber and yielding in the fastener, with formation of one plastic hinge; and Fig. 8(c) embedding in the timber and yielding in the fastener, with formation of three plastic hinges. The determination of the failure load for each failure mode was performed considering the following assumptions: (1) the thickness of the timber elements equal to half 
of the timber element diameter less half the slot thickness, (2) the washer $(19.08 \mathrm{~mm}$ internal diameter and $33.68 \mathrm{~mm}$ external diameter) completely in contact with the timber element surface, and (3) a characteristic value of the compression strength perpendicular to the grain equal to $6.9 \mathrm{MPa}$ (IPQ 1995). Regarding the dowel nut connections, the thickness of the timber elements was considered equal to half of the timber element diameter less half the longitudinal hole diameter.

To estimate the stiffness of the connections, the indications in Eurocode 5 (CEN 2002) for dowels and bolts without clearance were followed. It is important to note that the Eurocode 5 gives only the deformations due to embedment stresses in the timber. However, the experimental stiffness obtained for the dowel nut connections includes the deformation of the rod with $330 \mathrm{~mm}$ of length. For a proper comparison, the deformation of the rod was added to the deformation obtained from Eurocode 5.

The comparison between the experimental values and the ones obtained through the previously mentioned models are presented in Tables 7 and 8, for the central plate connections and the dowel nut connections, respectively. Regarding the central plate connections, it can be verified that the estimated load is, on average, $25.4 \%$ inferior to the experimental values. The failure mode $\mathrm{b}$ was generally, the governing one. Concerning stiffness, the estimated values were, on average, $28.2 \%$ higher than the experimental ones.

For the dowel nut connections the estimated failure load was, on average, $5.8 \%$ lower than the experimental values, the failure mode a generally being the governing one. Regarding stiffness, the estimated values were also, on average, $12.6 \%$ lower than the experimental ones.

For the glued-in rod connection no models exist to estimate the failure load. Nevertheless, for the studied configurations, an estimated failure load was obtained by considering the failure of one rod and the yield of the other three. Using this model, estimated failure loads of $61.31,104.58$, and $128.51 \mathrm{kN}$ were obtained for the 8,10 , and $12-\mathrm{mm}$ rod configurations, respectively. The estimated failure loads are $17.3 \%$ lower than the mean experimental failure values.

Table 7. Comparison between Experimental and Estimated Values for Central Plate Connections

\begin{tabular}{lcccc}
\hline & \multicolumn{4}{c}{ Central plate connection } \\
\cline { 2 - 5 } & $\begin{array}{c}F \text { exp. } \\
(\mathrm{kN})\end{array}$ & $\begin{array}{c}F \text { est. } \\
(\mathrm{kN})\end{array}$ & $\begin{array}{c}K_{s} \text { exp. } \\
(\mathrm{kN} / \mathrm{mm})\end{array}$ & $\begin{array}{c}K_{s} \text { est. } \\
(\mathrm{kN} / \mathrm{mm})\end{array}$ \\
\hline Mean & 112.0 & 83.6 & 31.6 & 40.5 \\
Max & 154.6 & 96.2 & 69.1 & 55.2 \\
Min & 70.8 & 67.8 & 15.6 & 27.9 \\
Std & 18.3 & 5.5 & 10.0 & 6.0 \\
Number of tests & 47 & 47 & 47 & 47 \\
\hline
\end{tabular}

Table 8. Comparison between Experimental and Estimated Values for Dowel Nut Connections

\begin{tabular}{lcccc}
\hline & \multicolumn{4}{c}{ Dowel nut connection } \\
\cline { 2 - 5 } & $\begin{array}{c}F \text { exp. } \\
(\mathrm{kN})\end{array}$ & $\begin{array}{c}F \text { est. } \\
(\mathrm{kN})\end{array}$ & $\begin{array}{c}K_{s} \text { exp. } \\
(\mathrm{kN} / \mathrm{mm})\end{array}$ & $\begin{array}{c}K_{s} \text { est. } \\
(\mathrm{kN} / \mathrm{mm})\end{array}$ \\
\hline Mean & 94.9 & 89.4 & 29.3 & 25.6 \\
Max & 147.4 & 126.5 & 70.5 & 33.0 \\
Min & 52.2 & 62.0 & 15.1 & 19.7 \\
Std & 20.8 & 15.2 & 11.9 & 3.2 \\
Number of tests & 58 & 58 & 113 & 58 \\
\hline
\end{tabular}

Regarding the stiffness of glued-in rods connections, an annex from a draft version of part 2 of Eurocode 5 (CEN 2003) presented an expression for the determination of $K_{s}$ of each rod $\left(K_{s}\right.$ $=0.005 d^{1.8} \rho^{1.5}$ ) having as input the rod diameter $(d)$ and timber density $(\rho)$. Applying such expression, mean values of 11.1, 17.4, and $24.2 \mathrm{kN} / \mathrm{mm}$ were obtained, for the glued-in rod configurations of 8,10 , and $12-\mathrm{mm}$ rods, respectively. Comparing these values with the ones presented in Table 3 , it is clear that this expression yielded much lower stiffness values than the experimental counterparts.

\section{Conclusions}

This paper presents a study regarding the mechanical behavior of three types of connections aiming structural applications with Portuguese maritime pine roundwood small diameter poles: central plate connections, dowel nut connections, and glued-in rod connections. The latter uses three different rod diameters.

The glued-in rods connection showed a failure governed by the steel for an adhesive layer thickness of $1 \mathrm{~mm}$ and a bonding length of 10 times the rod diameter. This type of connection with $12-\mathrm{mm}$ rods showed the highest average failure load, with $155 \mathrm{kN}$ and a mean stiffness of $171.6 \mathrm{kN} / \mathrm{mm}$. The failure of the central plate connections was simultaneously governed by both the wood and the steel, with a mean failure load of $112.0 \mathrm{kN}$ and a mean stiffness of $31.6 \mathrm{kN} / \mathrm{mm}$. In the case of dowel nut connections, the failure was caused by splitting of the wood, presenting almost no plastic deformations, with a mean failure load of $94.9 \mathrm{kN}$ and a mean stiffness of $29.3 \mathrm{kN} / \mathrm{mm}$.

Despite the differences in the mean failure load of all types of connections, the fifth percentile of the failure tension stress applied in the timber element of the connections was similar, varying between 6.6 and $7.6 \mathrm{MPa}$.

The glued-in rod connections were the ones with lower mean deformations for the maximum load, whereas the central plate connections were those with the higher mean value. These connections also underwent significant plastic deformation before failure.

The studied connections present a coefficient of variation of stiffness between 31.6 and $42.9 \%$. That coefficient was lower for the failure load (between 1.1 and 21.9\%). Indeed, the glued-in rod connections showed the lower failure load coefficient of variation, from 1.4 to $3.2 \%$, yielding a fifth percentile value very close to the mean value.

The European Yield Model formulations were applied to the central plate and dowel nut connections. On the basis of the obtained results it is possible to state that this model could be applied, with acceptable errors, to estimate the failure load of the dowel nut connections. On the other hand, the estimated failure load for the central plate connections was simulated with a higher average error equal to $25.4 \%$. It is also important to note that the simulated failure loads were, generally, lower than the experimental ones.

The formulations of the Eurocode 5, regarding stiffness, were applied to the central plate and dowel nut connections. It was concluded that the model can be applied, with acceptable errors, to estimate the stiffness of the dowel nut connections. Regarding the central plate connections, the Eurocode 5 model provided neither accurate nor safe values for the stiffness. Therefore, more tests should be performed to better understand the higher errors obtained in both the stiffness and failure load, for this connection. The present version of Eurocode 5 does not prescribe any calculation models for the glued-in rods. Therefore, a model was suggested for the failure load of the connections considering the failure of one rod and the yield of the other three. The simulated results showed that the assumed model gives, with moderate error, conservative values. 
Among the three types of studied connections, the glued-in rod was the one that showed, clearly, better performance, in terms of ductility, load-carrying capacity, or stiffness. This type of connection presented a ductile behavior, higher mean failure load and stiffness, and, because of its low failure load variation, a high fifth percentile failure load. As a result, although the other types of connections presented mean failure load higher than the 8-mm glued-in rods did, the fifth percentiles are similar. This is particular significant once the mechanical performance improved significantly when 10 - and 12-mm rods were used. Moreover, the glued-in rods connections are easier to assembly than the other studied connections and with less visible metallic parts, which results in a more visually appealing connection.

\section{Acknowledgments}

This study has been supported by Fundaçãopara a Ciência e Tecnologia, with the scholarship SFRH/BD/44909/2008, and by QREN, with funds from Fundo Europeu de Desenvolvimento Regional (FEDER), under the Programa Operacional de Factores de Competitividade, with the research project PTDC/ECM/099833/2008.

\section{References}

Burton, R., Dickson, M., and Harris, R. (1998). "The use of roundwood thinnings in buildings: A case study." Build. Res. Inf., 26(2), 76-93.

European Committee for Standardization (CEN). (1991). "Timber structures: Joints made with mechanical fasteners: General principles for the determination of strength and deformaton characteristics." $E N-26891$, Brussels, Belgium.

European Committee for Standardization (CEN). (2002). "Design of timber structures Part 1-1." Eurocode 5, Brussels, Belgium.

European Committee for Standardization (CEN). (2003). "Design of timber structures Part 2." Eurocode 5, Brussels, Belgium.

Chans, D. O., Cimadevila, J. E., and Gutiérrez, E. M. (2009). "Influence of the geometric and material characteristics on the strength of glued joints made in chestnut timber." Mater. Des., 30(4), 1325-1332.

Dias, A. M. P. G., Cruz, H. M. P., Lopes, S. M. R., and van de Kuilen, J. W. (2010). "Stiffness of dowel-type fasteners in timber-concrete joints." Struct. Build., 163(SB4), 257-266.

Dias, A. M. P. G., Lopes, S. M. R., van de Kuilen, J. W., and Cruz, H. M. P. (2007). "Load-carrying capacity of timber-concrete joints with doweltype fasteners." J. Struct. Eng., 133(5), 720-727.
Eckelman, C. A., and Senft, J. F. (1995), "Truss system for developing countries using small diameter roundwood and dowel nut construction." Forest Prod. J., 45(10), 77-80.

Houtman, R., Groot, C. J. W. P., and Ende, G. d. (1998), "Maximum strength of wire-laced dowel joints for round wood." World Conf. of Timber Engineering (WCTE), Swiss Federal Institute of Technology, Zurich, Switzerland, 161-168.

Huybers, P. (1996). "The structural application of thin roundwood poles in building." Final Rep. for Project FAIR-CT-95-0091 Task 2A, Delft Univ. of Technology, Delft, Netherlands.

Instituto Português da Qualidade (IPQ). (1995). "Madeira de pinheiro bravo para estruturas." NP4305, Lisbon, Portugal.

Kuilen, J. W. G. V. d. (1999). "Duration of load effects in timber joints." Ph.D. thesis, Delft Univ. of Technology, Delft, Netherlands.

Lukindo, A. R., Chastain, J. P., and Janni, K. A. (1997). "Techniques for making connections in small diameter timber roundwood members." Wood Design Focus, 8(1), 14-22.

Lukindo, A. R., Janni, K. A., and Larson, T. D. (1998). "Reinforcement properties of a ridged plate in a bolted flitch-plate connection." Am. Soc. Agricult. Eng., 41(1), 187-192.

Morgado, T., Rodrigues, J., Machado, J., Dias, A., and Cruz, H. (2009). "Bending and compression strength of Portuguese Maritime pine smalldiameter poles." Forest Prod. J., 59(4), 23-28.

Sluis, E. W. P., Groot, C. J. W. P., and Ende, G. d. (1998). "The block shear joint, a new joint for roundwood structures." World Conf. of Timber Engineering (WCTE), Swiss Federal Institute of Technology, Zurich, Switzerland, 268-276.

Stern, E. G. (2001). "Construction with small-diameter roundwood.” Forest Prod. J., 51(4), 71-82.

USDA (2010). Wood handbook: Wood as an engineering material, Forest Products Laboratory, Madison, WI, 4.1-4.45.

Vale, C. M., Lima, J. T., and Carrasco, E. V. M. (2011). "Comportamento ao arrancamento de pinos metálicos embutidos e colados em peças de madeira roliça de pequeno diâmetro." CIMAD 11, Banema, Porto, Portugal.

Wolfe, R. (2000). "Research Challenges for Structural use of small-diameter round timbers." Forest Prod. J., 50(2), 21-29.

Wolfe, R. W., King, J. R., and Gjonolli, A. (2000). "Dowel-nut connection in douglas-fir peeler cores." Research Paper FPL-RP-586, USDA, Washington, DC.

Yeates, A. (1999). "Use of plantation hardwood thinnings as roundwood in construction." Gottstein Fellowship Rep., Gottstein Memorial Trust, Melbourne, Australia. 